\title{
Thermal Stress Distribution and Evolution of Concrete Particles under Microwave Irradiation
}

\author{
Qin Like $^{1, *}$, Li Yong $^{2}$, Dai Jun ${ }^{1}$ and Teng Pengfei \\ ${ }^{1}$ School of Architecture and Civil Engineering, Xi'an University of Science and Technology, Xi'an 710054, China \\ ${ }^{2}$ School of Science, Xi'an University of Science and Technology, Xi'an 710054, China \\ ${ }^{3}$ University of Hong Kong, 10 Sassoon Road, Pok Fu Lam, Hong Kong
}

Received 1 April 2016; Accepted 23 May 2016

\begin{abstract}
Microwave heating could increase the efficiency of eliminating mortar in recycled concrete aggregate and improving recycled concrete aggregate quality. A 2D finite element model of microwave oven and concrete particles was established to study the distribution and evolution law of thermal stress field in concrete particles. In this model, influences of power, time, aggregate radius, and mortar thickness were considered. Results showed that the temperature and stress of concrete particles in a microwave field are in approximately symmetric distribution. The maximum stress of mortar is on the interface between mortar and the recycled concrete aggregate. The maximum tensile stress of mortar and recycled concrete aggregate was proportional to microwave power and irradiation time but inversely proportional to aggregate radius. The maximum tensile stress of mortar and recycled concrete aggregate initially increased and then decreased with increased mortar thickness. Given the same energy consumption, higher microwave power led to stronger tensile stress of concrete particles and higher energy use. With reasonable irradiation time, the mortar produced cracks, whereas the recycled concrete aggregate remained integral.
\end{abstract}

Keywords: Concrete particles, Recycled concrete aggregate, Microwave irradiation, Thermal stress

\section{Introduction}

Recycled concrete aggregate is a mixture of waste concrete debris in certain proportions and represents the realization of waste concrete recycling [1-4]. Given the adhered original mortar, recycled concrete aggregate has low apparent density, high water absorption, and low strength [5-7]. At present, recycled concrete aggregate is prepared via many methods, such as mechanical beneficiation, thermalmechanical beneficiation, and acid soaking beneficiation [811]. Among them, the heating system of thermal-mechanical beneficiation could be divided into traditional heating system and microwave heating system. Compared with traditional heating, microwave heating has advantages of internal heating, rapid heating, selective heating, and simple control; therefore, microwave heating could increase efficiency of eliminating mortar in recycled concrete aggregate.

\section{State of the art}

Microwave heating system, which uses different electromagnetic properties of concrete aggregate and mortar, is identified as an effective way to eliminate surface mortar. Under quick selective concrete heating by microwave, concrete aggregate and mortar expand to different extents; such expansion causes micro-cracks on the aggregate-mortar

\footnotetext{
*E-mail address: 422576294@qq.com ISSN: 1791-2377 @ 2016 Eastern Macedonia and Thrace Institute of Technology. All rights reserved.
}

interface, thereby reducing energy consumption for mechanical crushing and increasing elimination efficiency of mortar on recycled concrete aggregate surface. A. Akbarnezhad et al. [14, 15] indicated that microwave irradiation could eliminate mortar adhered on concrete particles effectively and improve mechanical properties of recycled concrete aggregates by test and numerical simulation. Compared to other methods, microwave irradiation has lower energy consumption and shorter processing time. N. Lippiatt et al. [16] conducted a microwave irradiation test on concrete particles and verified microwave irradiation effect via an impact test. Test results showed that concrete particles are severely damaged by exposure to microwaves and that the damage degree is positively correlated with irradiation time. Microwavetreated particles showed improved comminution properties and liberation of both aggregate and cement phases after impact fracture; both increase monotonically with duration of exposure to microwaves. J.Z. Xiao et al. [17] tested physical and mechanical properties of microwave modified recycled coarse concrete aggregates and recycle coarse concrete. This microwave modification was compared with traditional pure mortar beneficiation and mechanical beneficiation; results showed that microwave modification results in more ideal performance of recycled concrete aggregates.

The use of microwave heating system to eliminate mortar on the recycled concrete aggregate surface has yielded certain research results. However, research is inadequate on thermal stress distribution characteristics in concrete under microwave irradiation and influencing factors. Therefore, this paper studied thermal stress distribution in concrete particles under microwave 
irradiation, as well as its evolution via the finite element method, to further explore the mortar elimination mechanism of microwave irradiation and provide theoretical basis for design optimization of microwave equipments.

\section{Methodology}

\subsection{Computing method}

Electromagnetic field theory indicates that the electromagnetic field problem is used to solve the Maxwell equations under the given boundary conditions:

$$
\begin{aligned}
& \nabla \times \mathbf{H}=\mathbf{J}+\frac{\partial \mathbf{D}}{\partial t} \\
& \nabla \times \mathbf{E}=-\frac{\partial \mathbf{B}}{\partial t} \\
& \nabla \cdot \mathbf{D}=\rho \\
& \nabla \cdot \mathbf{B}=0
\end{aligned}
$$

where $\mathbf{E}$ is electric intensity vector, $\mathbf{D}$ is potentiometer vector, $\mathbf{H}$ is magnetic intensity vector, $\mathbf{B}$ is magnetic flux density, $\mathbf{J}$ is conduction current vector, $\rho$ is free charge, and $t$ is time.

The continuous basic equation is

$$
\nabla \cdot \mathbf{J}=\frac{\partial \rho}{\partial t}
$$

In Equations (1)-(5), only three variables are independent. Their constitutive relationships are:

$$
\begin{aligned}
& \mathbf{D}=\varepsilon \mathbf{E}=\varepsilon_{\mathrm{r}} \varepsilon_{0} \mathbf{E} \\
& \mathbf{B}=\mu \mathbf{H}=\mu_{\mathrm{r}} \mu_{0} \mathbf{H} \\
& \mathbf{J}=\sigma \mathbf{E}
\end{aligned}
$$

where $\varepsilon_{0}$ is dielectric constant in vacuum, $\varepsilon_{\mathrm{r}}$ is relative dielectric constant of materials, $\mu_{0}$ is magnetic conductivity in vacuum, $\mu_{\mathrm{r}}$ is relative magnetic conductivity of materials, and $\sigma$ is electric conductivity.

After the electric field is solved from Maxwell equations, microwave power consumed by per unit volume of material can be calculated from the following equation:

$$
P_{d}=\frac{1}{2} \omega \varepsilon_{0} \varepsilon_{\mathrm{r}}^{\prime \prime}|\mathbf{E}|^{2}
$$

where $P_{d}$ is power density, $\omega$ is scattering frequency of microwave, $\varepsilon_{r}^{\prime \prime}$ is material loss coefficient.

Neglecting heat conduction of water in materials, heat conduction equation can be expressed as

$$
\rho c \frac{\partial T}{\partial t}=-\nabla \cdot(-K \nabla T)+P_{d}
$$

where $\rho$ is material density, $t$ is irradiation time, $T$ is temperature, $\nabla$ is gradient operator, $c$ is specific heat, $K$ is thermal conductivity, and $P_{d}$ is distributed heat sources.

Total strain component in material could be expressed as:

$$
\varepsilon=\varepsilon^{\sigma}+\varepsilon^{T}
$$

where $\varepsilon^{\sigma}$ is strain caused by elastic stress and $\varepsilon^{T}$ is isotropic thermal strain caused by temperature. In the $2 \mathrm{D}$ plane, they could be expressed as:

$\varepsilon^{\sigma}=\left\{\begin{array}{c}\varepsilon_{x} \\ \varepsilon_{y} \\ \gamma_{x y}\end{array}\right\}=\left[\begin{array}{c}\frac{\partial u}{\partial x} \\ \frac{\partial v}{\partial y} \\ \frac{\partial v}{\partial x}+\frac{\partial u}{\partial y}\end{array}\right]=\left[\begin{array}{cc}\frac{\partial}{\partial x} & 0 \\ 0 & \frac{\partial}{\partial y} \\ \frac{\partial}{\partial y} & \frac{\partial}{\partial x}\end{array}\right]\left[\begin{array}{l}u \\ v\end{array}\right]$

where $u$ and $v$ are displacements on $x$ and $y$ directions.

$\varepsilon^{T}=\left\{\begin{array}{c}\varepsilon_{x}^{T} \\ \varepsilon_{y}^{T} \\ \gamma_{x y}^{T}\end{array}\right\}$

The stress-strain relation is:

$$
\{\sigma\}=[D]\{\varepsilon\}
$$

where $[D]$ is tensor of constitutive parameter. Under plane stress state, constructive parameter of isotropic material is:

$[D]=\frac{E}{1-v^{2}}\left[\begin{array}{ccc}1 & v & 0 \\ v & 1 & 0 \\ 0 & 0 & \frac{1-v}{2}\end{array}\right]$

$\varepsilon^{T}=\left\{\begin{array}{c}\alpha \Delta T \\ \alpha \Delta T \\ 0\end{array}\right\}$

Under plane strain, constructive parameter of isotropic material is:

$[D]=\frac{E(1-v)}{(1+v)(1-2 v)}\left[\begin{array}{ccc}1 & \frac{v}{1-v} & 0 \\ \frac{v}{1-v} & 1 & 0 \\ 0 & 0 & \frac{1-2 v}{2(1-v)}\end{array}\right]$

$\varepsilon^{T}=(1+v)\left\{\begin{array}{c}\alpha \Delta T \\ \alpha \Delta T \\ 0\end{array}\right\}$

where $\alpha$ is temperature expansion coefficient of material and $\Delta T$ is temperature increment. 


\subsection{Calculation model}

The 2D plane finite element model of microwave oven and concrete particles is shown in Fig. 1. The microwave oven consists of microwave cavity and waveguide. The microwave cavity is $500 \mathrm{~mm}(\mathrm{~W}) \times 350 \mathrm{~mm}(\mathrm{H})$ and the WR340 waveguide is $86.36 \mathrm{~mm}(\mathrm{~W}) \times 100 \mathrm{~mm}(\mathrm{H})$, which is put above the microwave cavity. The WR340 waveguide adopts $\mathrm{TE}_{10}$ patter and its frequency is $2.45 \mathrm{GHz}$. Concrete particles comprise aggregates (granite) and mortar (cement mortar with a water-cement ratio of 0.45 ). Performance parameters $[14,18,19]$ of the material are listed in Table 1. Concrete particles are in the center of the microwave cavity. Their vertical diameter is $\mathrm{AD}$, which interacts with the aggregate-mortar boundary at points B and C. Point O is the center of concrete particles.

During calculation, we hypothesized that (1) initial temperature of concrete particles is $20^{\circ} \mathrm{C}$. (2) Given short microwave irradiation time, the outward thermal irradiation magnitude of concrete particles is low. Concrete particle boundary is assumed heat insulation. (3) Concrete particle boundary is free boundary.

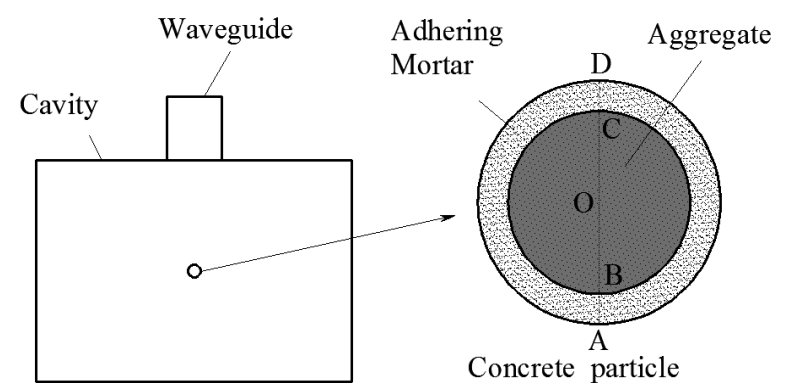

Fig.1. Numerical model

Table 1. Electromagnetic, thermal, and structural properties of aggregate and mortar used for simulation [14, 18, 19]

\begin{tabular}{l|l|l}
\hline & Aggregate & Mortar \\
\hline Dielectric constant & 6 & 6.42 \\
Electric conductivity $(\mathrm{S} / \mathrm{m})$ & 0.071 & 0.372 \\
Thermal conductivity $\left(\mathrm{K} / \mathrm{m}^{\circ} \mathrm{C}\right)$ & 4.3 & 1.3 \\
Expansion coefficient $\left(10^{-6} /{ }^{\circ} \mathrm{C}\right)$ & 11 & 19 \\
Specific heat $\left(\mathrm{J} / \mathrm{kg}^{\circ} \mathrm{C}\right)$ & 800 & 1600 \\
Modulus of elasticity $(\mathrm{GPa})$ & 50 & 25 \\
Density $\left(\mathrm{kg} / \mathrm{m}^{3}\right)$ & 2800 & 1650 \\
Poisson's ratio & 0.25 & 0.15 \\
Tensile strength $(\mathrm{MPa})$ & 7 & 2.8 \\
\hline
\end{tabular}

\section{Result analysis and discussion}

\subsection{Temperature and stress distribution}

Fig. 2 is the cloud chart of electric field distribution in microwave cavity when $\mathrm{P}=1 \mathrm{~kW}$. The electric field is distributed symmetrically but unevenly in the microwave cavity. The maximum electric field is in the center of the cavity. Heating rate of dielectric material in microwave field is determined by electric field intensity. Therefore, position of concrete particles in the microwave oven determines heating rate. The concrete particles composed of aggregate $(\mathrm{OB}=3 \mathrm{~mm})$ and mortar (thickness $=3 \mathrm{~mm})$ are put in the microwave cavity center. Cloud charts of temperature and tensile stress of concrete particles $20 \mathrm{~s}$ later are shown in Figs. 3 and 4. Although electric field is distributed unevenly in the microwave cavity, electric field in the small concrete particle changes slightly. Temperature and tension of concrete particles are distributed approximately symmetrically around the center. Given that loss coefficient of mortar is higher than that of aggregate, mortar temperature is generally higher than aggregate temperature. The highest temperature of mortar $\left(72.0^{\circ} \mathrm{C}\right)$ is at $\mathrm{D}$; the temperature at $\mathrm{A}$ is $69.4^{\circ} \mathrm{C}$. The lowest temperature at aggregate center is $62.5^{\circ} \mathrm{C}$. In Fig. 4 , tensile stress of aggregate is generally higher than that of mortar. Tensile stress curve of concrete particles along $\mathrm{AD}$ is shown in Fig. 5. Tensile stress of mortar increases from outer surface into inner mortar, whereas tensile stress curve of aggregate is relatively smoother. The tensile stress curve has inflection points at $\mathrm{B}$ and $\mathrm{C}$. The maximum tensile stress of mortar $(5.4 \mathrm{MPa})$ is at the mortar-aggregate interface, which is higher than the tensile strength. Concrete particles are produced first at the mortar-aggregate interface. The maximum tensile stress of aggregate $(5.8 \mathrm{MPa})$ is close to the aggregate center and is smaller than tensile strength. Therefore, no crack is developed in aggregate.

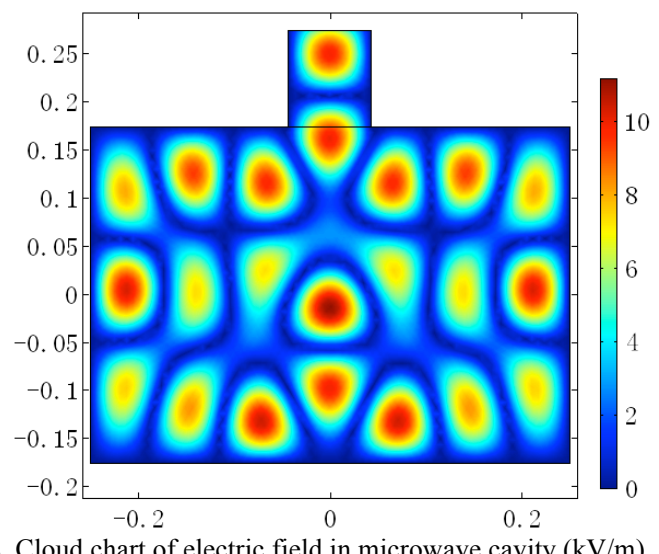

Fig.2. Cloud chart of electric field in microwave cavity $(\mathrm{kV} / \mathrm{m})$ $(\mathrm{P}=1 \mathrm{~kW}, \mathrm{t}=20 \mathrm{~s})$

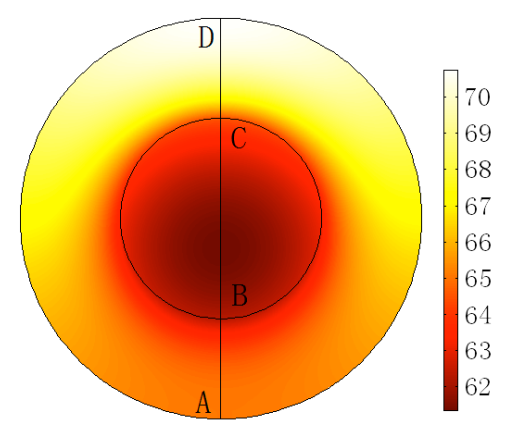

Fig.3. Temperature distribution in concrete particles $\left({ }^{\circ} \mathrm{C}\right)(\mathrm{P}=1 \mathrm{~kW}$, $\mathrm{t}=20 \mathrm{~s})$

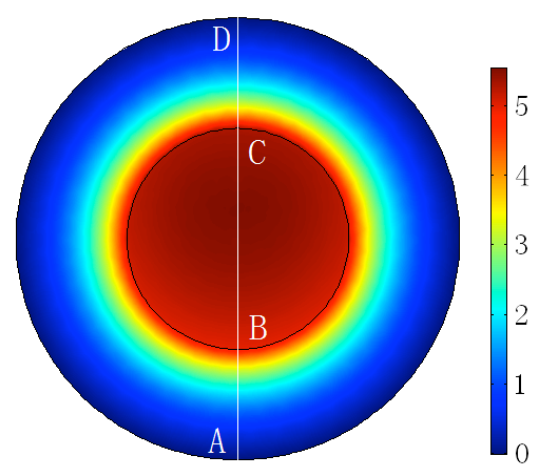

Fig.4. Cloud chart of tensile stress in concrete particles (MPa) 
$(\mathrm{P}=1 \mathrm{~kW}, \mathrm{t}=20 \mathrm{~s})$

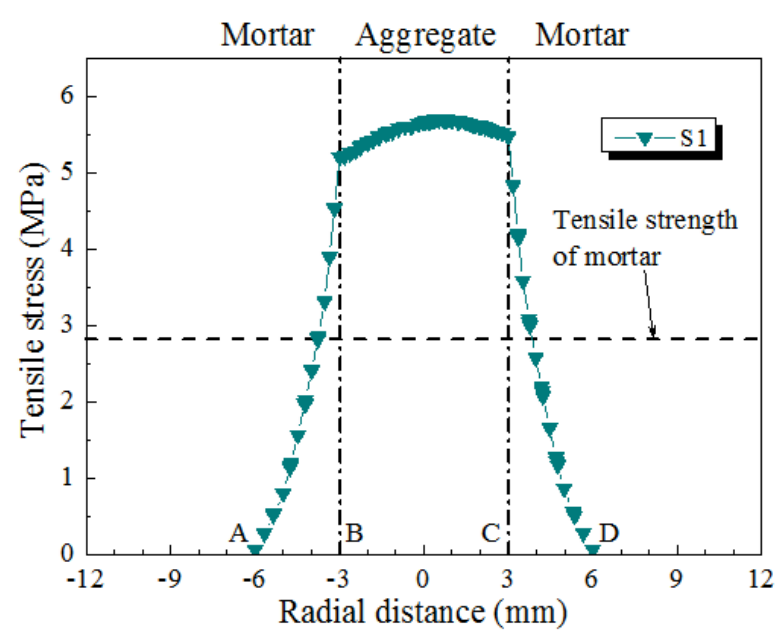

Fig.5. Tensile stress curve of concrete particles along AD $(\mathrm{P}=1 \mathrm{~kW}$, $\mathrm{t}=20 \mathrm{~s})$

\subsection{Effect of microwave power and irradiation time}

Tensile stress distribution of concrete particles along AD under different irradiation times $(\mathrm{P}=0.8 \mathrm{~kW})$ is shown in Fig. 6. Stress distribution pattern of concrete particles remains same under different irradiation times. Width of tensile stress curve of mortar in tensile strength (AB and $\mathrm{CD}$ ) increases gradually with irradiation time; such an increase indicates that cracks in mortar are developed on the mortaraggregate interface and gradually extend to concrete particle surface. When irradiation time increases to $35 \mathrm{~s}$, the maximum tensile stress in aggregate is higher than the tensile strength; cracks are also developed in aggregate. Thus, given a certain microwave power, a certain range of irradiation time is reasonable. In this reasonable range, cracks only exist in mortar, whereas the aggregate remains integral. Relation curves between the maximum tensile stress and irradiation time of mortar and aggregate are presented in Fig. 7. The maximum tensile stresses of mortar and aggregate increase as irradiation time at a similar growth rate. The reasonable irradiation time ranges between $11.8 \mathrm{~s}$ and $33.4 \mathrm{~s}$. When irradiation time is shorter than $11.8 \mathrm{~s}$, no crack is developed in mortar and it fails to achieve microwave-assisted sorting. When irradiation time is longer than $4 \mathrm{~s}$, cracks are developed in aggregate, thereby significantly damaging the aggregate quality.

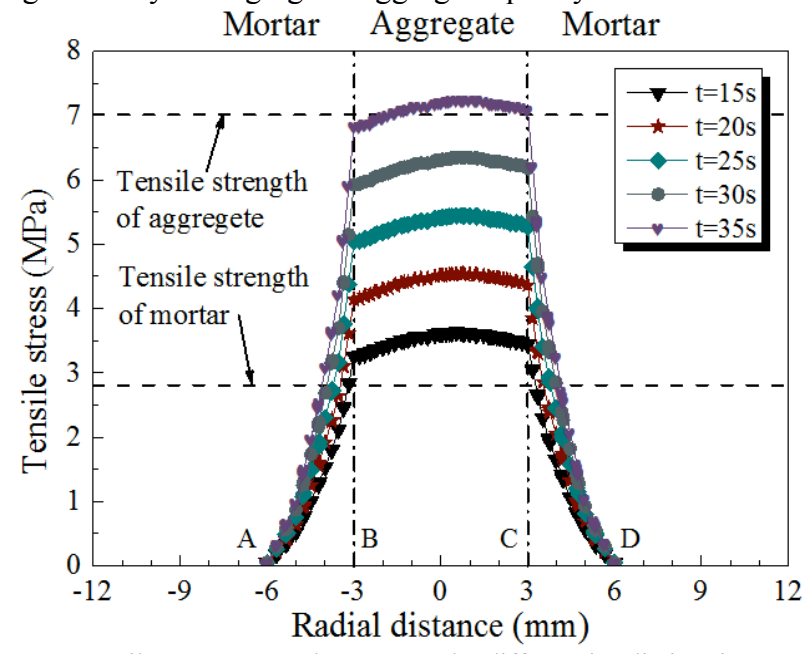

Fig. 6 Tensile stress curve along AD under different irradiation times $(\mathrm{P}=0.8 \mathrm{~kW})$

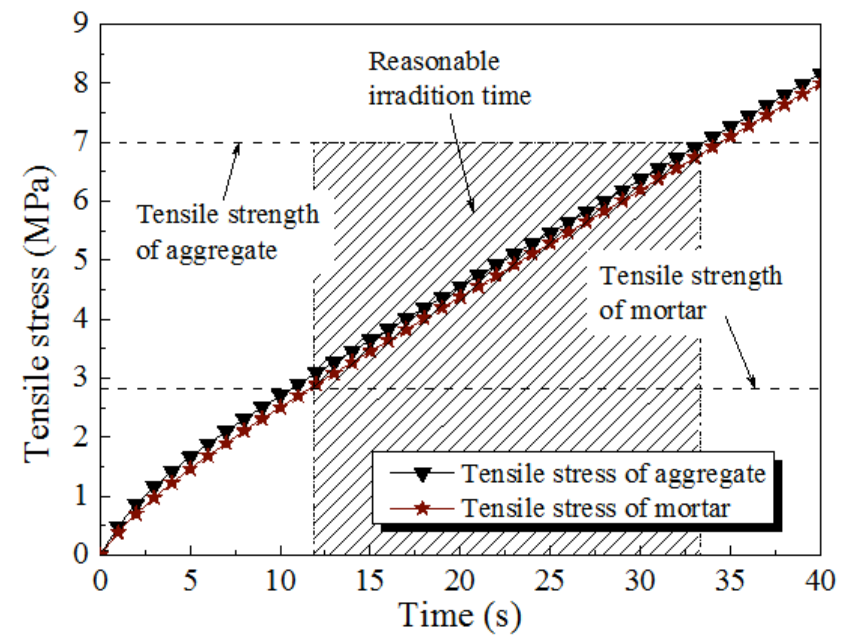

Fig. 7 Relation curves between the maximum tensile stress along AD and irradiation time of aggregate and mortar $(\mathrm{P}=0.8 \mathrm{~kW})$

Tensile stress distribution of concrete particles along AD under different microwave powers (irradiation time $=20 \mathrm{~s}$ ) is shown in Fig. 8. Given same irradiation time, tensile stress distribution of concrete particles is independent from microwave power. Width of $\mathrm{AB}$ and $\mathrm{CD}$ of mortar increases with microwave power. In other words, higher microwave power will cause greater mortar damage. The relation curves between the maximum tensile stress and microwave power of mortar and aggregate are shown in Fig. 9. For both mortar and aggregate, a linear growth relationship occurs between the maximum tensile stress and microwave power. When microwave irradiation time is $20 \mathrm{~s}$ and $\mathrm{P}<0.5 \mathrm{~kW}$, no crack is developed. When $\mathrm{P}>1.2 \mathrm{~kW}$, cracks are developed in aggregate.

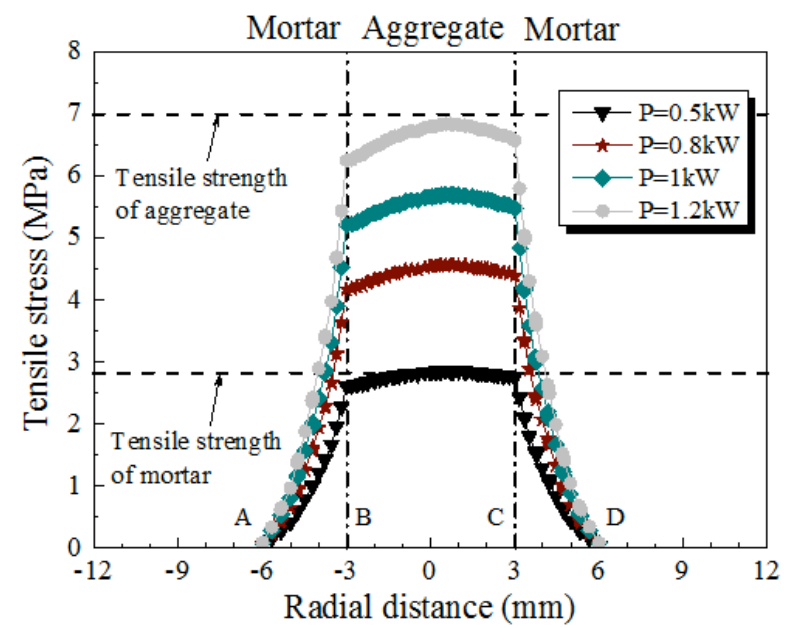

Fig. 8 Tensile stress curve along AD under different microwave powers $(\mathrm{t}=20 \mathrm{~s})$

To investigate irradiation efficiency of different microwave powers, stress distributions along $\mathrm{AD}$ under different energy consumption $(10 \mathrm{~kJ}$ and $20 \mathrm{~kJ})$ are shown in Figs.10 and 11. Under same microwave energy output, higher microwave power leads to stronger tensile stress in mortar and aggregate, as well as greater width of tensile stress of mortar in tensile strength. These results indicate that that higher microwave power could produce more cracks in mortar. Therefore, higher microwave power results in higher energy utilization, shorter irradiation time, and higher production efficiency. 


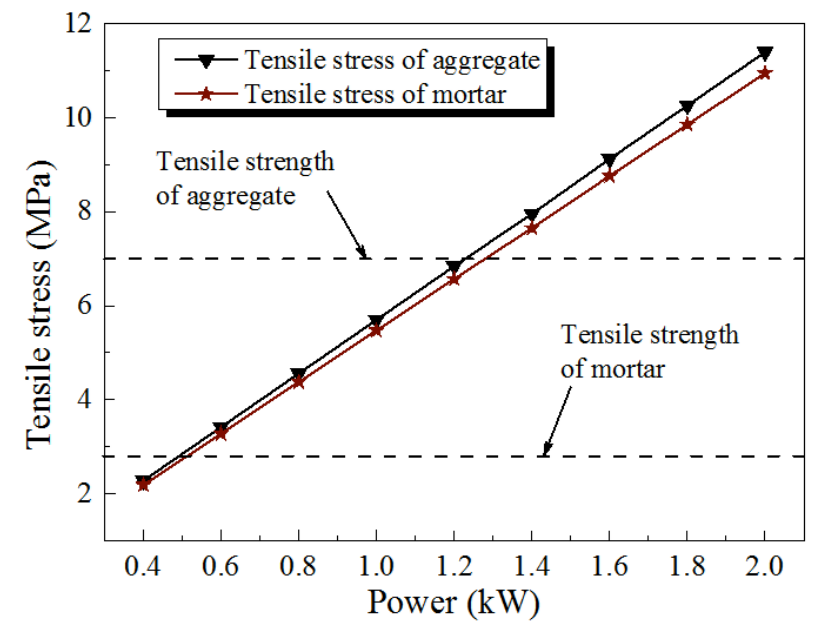

Fig. 9 Tensile stress curve along AD under different microwave powers $(\mathrm{t}=20 \mathrm{~s})$

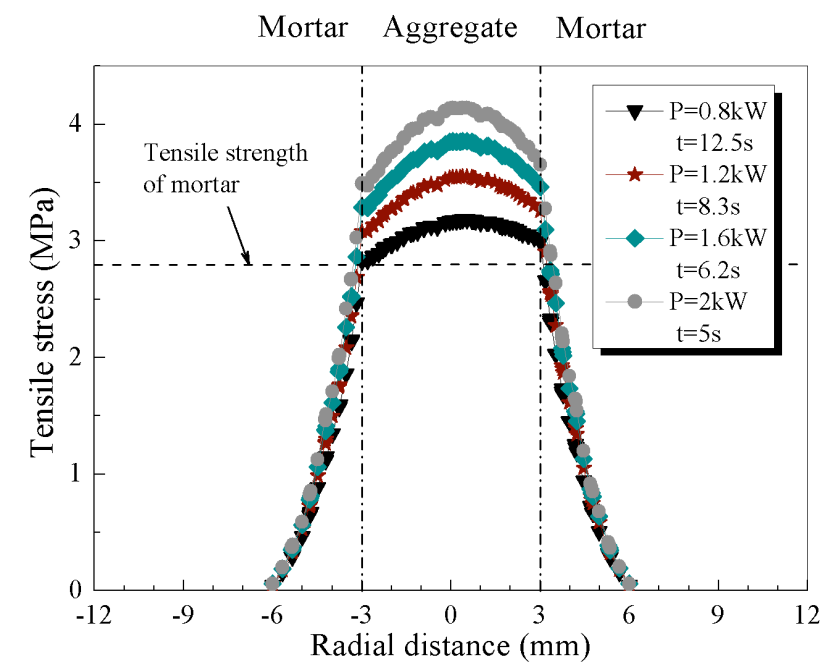

Fig. 10 Tensile stress curve along AD under different powers (energy consumption $=10 \mathrm{~kJ}$ )

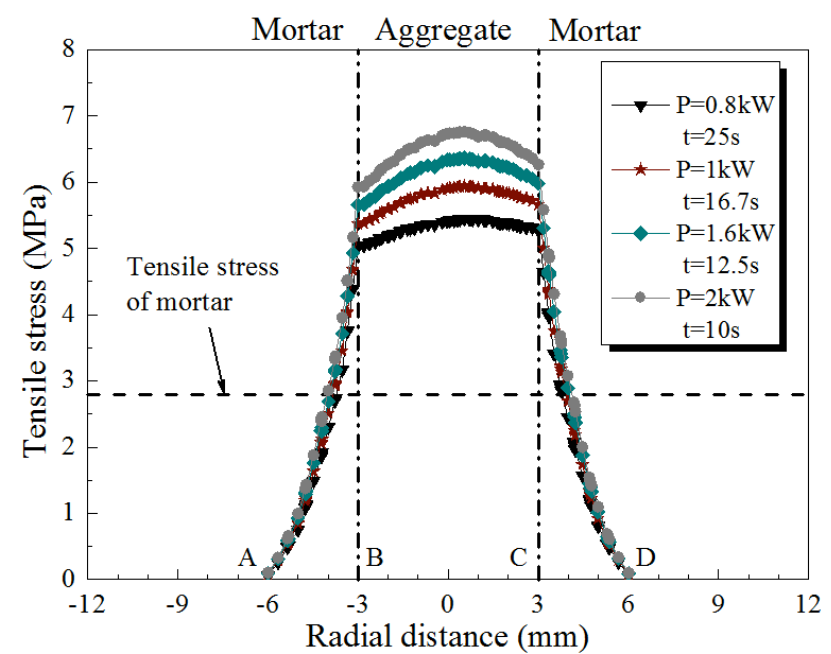

Fig. 11 Tensile stress curve along AD under different powers (energy consumption $=20 \mathrm{~kJ}$ )

\subsection{Effect of aggregate radius and mortar thickness}

Figure 12 shows the effect of aggregate radius on tensile stress (mortar thickness $=3 \mathrm{~mm}$ ). Aggregate radius slightly affects stress distribution. Given same mortar thickness, larger aggregate causes smaller tensile stress in concrete particles; the maximum tensile stresses of mortar and aggregate are closer to each other. Influences of aggregate radius on the maximum stress of mortar and aggregate are shown in Fig. 13. As aggregate radius increases, the maximum stress of mortar and aggregate decreases exponentially. When aggregate radius is smaller than $3.5 \mathrm{~m}$, cracks are developed in aggregate. When aggregate radius is bigger than $4.6 \mathrm{~mm}$, no crack is developed in mortar. Therefore, waste concrete particles will be screened before microwave irradiation. Using different microwave power and irradiation times to different sizes of concrete particles could effectively improve mortar elimination efficiency.

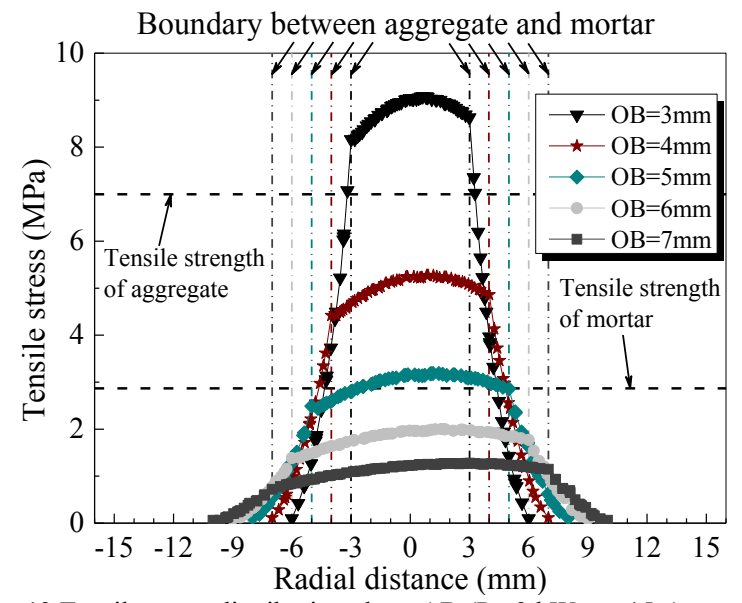

Fig. 12 Tensile stress distribution along $A D(P=2 k W, t=15 s)$

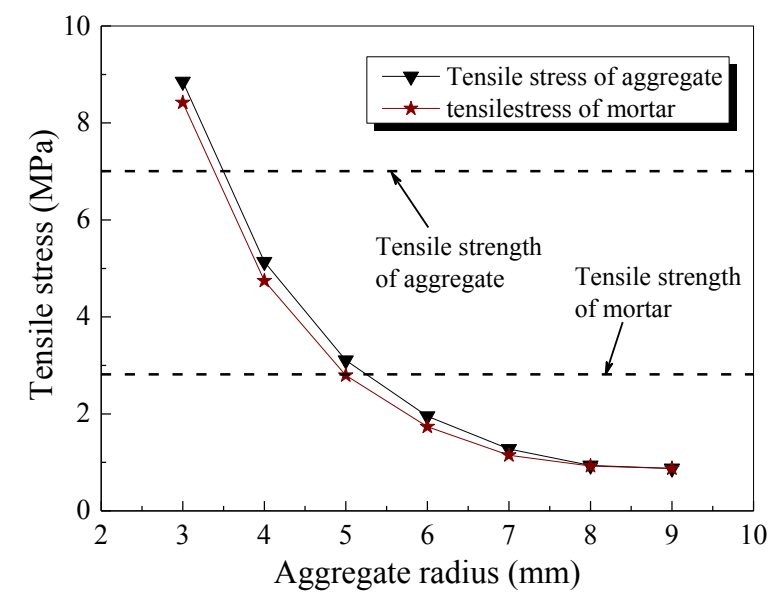

Fig. 13 Relation curves between the maximum stress of mortar and aggregate and aggregate radius $(\mathrm{P}=2 \mathrm{~kW}, \mathrm{t}=10 \mathrm{~s})$

Effect of mortar thickness on tensile stress is presented in Fig. 14 (aggregate radius $=3 \mathrm{~mm}$ ). Relation curves between the maximum tensile stress of mortar and aggregate and mortar thickness are shown in Fig. 15. Tensile stress distribution along $\mathrm{AD}$ remains the same as mortar thickness changes. The maximum tensile stresses of mortar and aggregate increase first and then decrease as mortar thickens. The growth rate is smaller than the decrease rate. Maximum tensile stress is achieved at $1.6 \mathrm{~mm}$ mortar thickness.

\subsection{Experimental verification}

Concrete particles were heated in the microwave heating system. The microwave heating system comprises three parts (Fig. 16). Concrete particle samples, which were heated for different times, are shown in Fig. $17(\mathrm{P}=2 \mathrm{~kW})$. Cracks were observed obviously on concrete particle samples. Crack development on concrete particle surface is positively correlated with microwave irradiation time. Concrete particle samples with different aggregate radii 
under same irradiation conditions are shown in Fig. 18. All concrete particles were cracked. Crack development is inversely proportional to aggregate radius. Mortar on concrete particle with the minimum aggregate radius was peeled off. Experimental observations are consistent with calculated results.

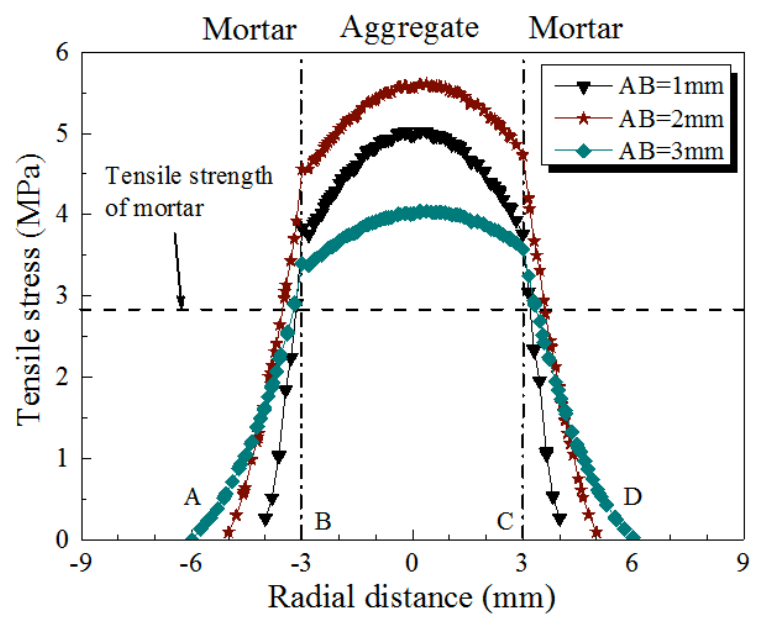

Fig. 14 Tensile stress distribution along AD under different mortar thickness $(\mathrm{P}=2 \mathrm{~kW}, \mathrm{t}=5 \mathrm{~s})$

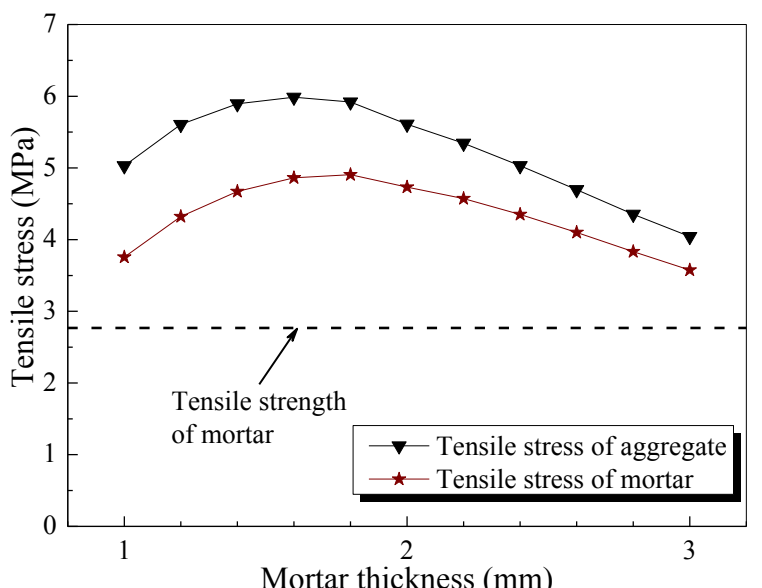

Fig. 15 Tensile stress distribution along AD under different mortar thickness $(\mathrm{P}=2 \mathrm{~kW}, \mathrm{t}=5 \mathrm{~s})$

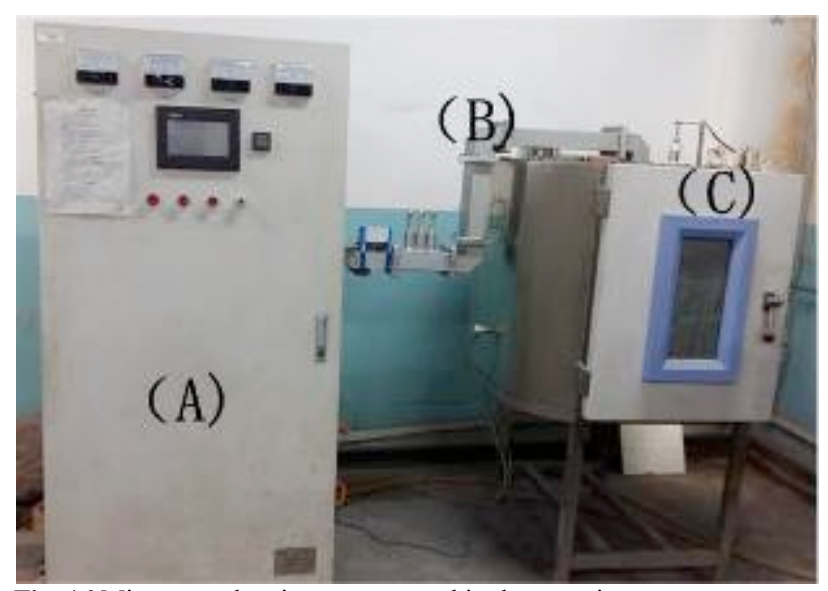

Fig. 16 Microwave heating system used in the experiment: (A) microwave apparatus, (B) waveguide, and (C) furnace chamber

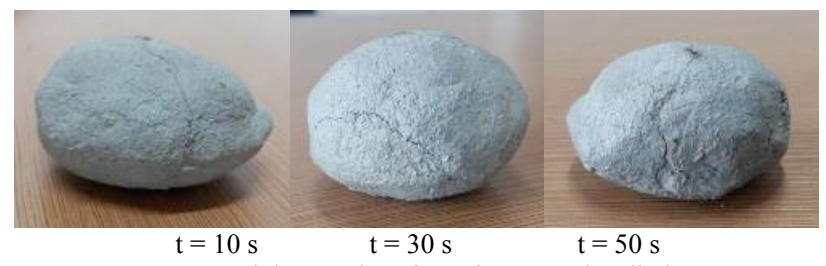

Fig. 17 Concrete particle samples after microwave irradiation

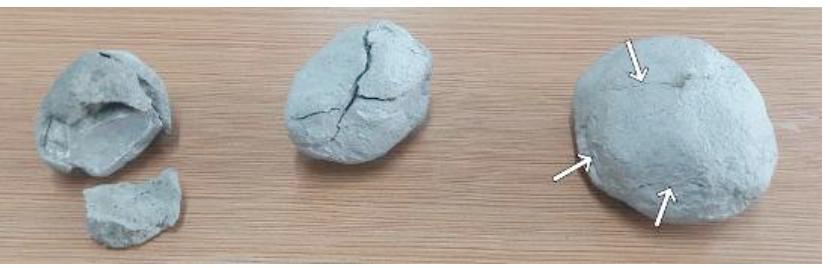

Fig. 18 Concrete particle samples with different aggregate radii after microwave irradiation

\section{Conclusions}

Microwave heating can improve the quality of recycled concrete aggregate by reducing the amount of the mortar that adheres to the recycled concrete aggregate particles, as shown from serial analyses of the 2D plane finite element model of concrete particles. We obtain several important conclusions, as follows.

(1) Under microwave irradiation, temperature and stress are in approximate central symmetric distribution in concrete particles. Compared to aggregate, mortar has higher temperature but smaller tensile strength. The maximum tensile stress of mortar is on the mortar-aggregate interface, while the maximum tensile stress of aggregate is in the aggregate center. Cracks on concrete particles are developed on the interface first and then extend to surface gradually.

(2) Tensile stress distribution of concrete particle under different microwave irradiation conditions is similar. The maximum tensile stresses of mortar and aggregate are proportional to irradiation time and power density. Given fixed microwave power a reasonable irradiation time range follows. When irradiation time is shorter than this range, no crack is developed on concrete particles. However, when irradiation time is longer than this range, cracks are developed in aggregate. Only within this reasonable irradiation time range does mortar crack, but the aggregate remains integral.

(3) The maximum tensile stresses of mortar and aggregate increase with aggregate radius, but they increase first and then decrease as mortar thickens. To improve microwaveassisted aggregate sorting efficiency, concrete particles will be screened before microwave irradiation and microwave power; furthermore, irradiation time will be determined based on concrete particle size.

(4) Given same energy consumption, higher microwave power results in greater width of tensile stress of mortar in tensile strength curve and more cracks in mortar. High microwave power could effectively improve energy utilization.

The conclusions obtained in the study can be applied to reveal the concrete destruction mechanism under microwave irradiation and provides technical support for efficiency prediction of eliminating mortar on recycled concrete aggregate. 


\section{Acknowledgements}

This work was supported by the Foundation of Shaanxi

Educational Committee (15JK1471), the China Postdoctoral
Science Foundation (2015M572580), and the National Natural Science Foundation of China (No. 51174159).

\section{References}

1. Y.D. Sun, J.Z. Xiao. "Aggregate of recycled concrete", Concrete, 176(6), pp. 2004,33-36

2. J.Z. Xiao, J.B. Li, C.H. Zhang. "On relationships between the mechanical properties of recycled aggregate concrete: an overview", Materials \& Structures, 39(290), 2006, pp. 655-64.

3. R. Major, S.V. Barai. "Studies on recycled aggregates-based concrete". Waste Management \& Research, 24(3), 2006, pp. 22533.

4. P. Chisun. "Recent studies on mechanical properties of recycled aggregate concrete in China - A review". Science China Technological Sciences, 55(6), 2012, pp. 1463-1480

5. N. Otsuki, S. Miyazato, W. Yodsudjai. "Influence of recycled aggregate on interfacial transition zone, strength, chloride penetration and carbonation of concrete". Journal of Materials in Civil Engineering, 15(5), 2003, pp. 443-451.

6. J.M. Khatib. "Properties of concrete incorporating fine recycled aggregate". Cement and Concrete Research, 35 (4), 2005, pp. 763 769 .

7. S.W. Tabsh, A.S. Abdelfatah. "Influence of recycled concrete aggregates on strength properties of concrete". Construction and Building Materials. 23(2), 2009, pp. 1163-1167.

8. T. Yonezawa, Y. Kamiyama, K. Yanagibashi, et al. "A study on a technology for producing high quality recycled coarse aggregate". Journal of the Society of Materials Science. 50(8), 2001, pp. 835842

9. H. Shima, H. Tateyashiki, R. Matsuhashi, et al. "Advanced concrete recycling technology and its applicability assessment through inputoutput analysis". Journal of advanced concrete technology. 3(3) 2005, pp. 53-67.
10. M.S.D. Juan, P.A. Gutierrez. "Study on the influence of attached mortar content on the properties of recycled concrete aggregate". Construction and Building Materials. 23(2), 2009, pp. 872-877.

11. V. Tam, C.M. Tam, K.N. Le. "Removal of cement mortar remains from recycled aggregate using pre-soaking approaches". Recycling and Resource Conservation, 50(1), 2007, pp. 82-101.

12. X. N. Chen, J. Dai, Z. Meng. "Microwave-assisted mechanic technique of improving the quality of recycled concrete aggregates". Journal of Xi'an University of science and technology, 33(5), 2013, pp. 604-608.

13. J. Dai, Q. Wang. "Preliminary studies on new beneficiation technique of recycled concrete aggregate", Concrete, 50(8), 2014, pp. 133-135.

14. A. Akbarnezhad, K.C.G. Ong, M.H. Zhang, et al. "Microwaveassisted beneficiation of recycled concrete aggregates". Construction and Building Materials. 25 (8), 2011, pp. 3469-3479.

15. A. Akbarnezhad, K.C.G. Ong. "Microwave decontamination of concrete". Magazine of Concrete Research". 62(12), 2010, pp. 879885.

16. N. Lippiatt, F. Bourgeois. "Investigation of microwave-assisted concrete recycling using single-particle testing", Minerals Engineering, 31 (4), 2012, pp. 77-81.

17. J.Z. Xiao, L. Wu, Y.H Fan. "Test on modification of recycled coarse aggregate by microwave heating". Concrete. 31(7), 2012, pp. 55-57

18. Y.S. Touloukian, W.R. Judd, R.F. Roy. "Physical Properties of Rocks and Minerals", New York: McGraw Hill, USA, 1989, pp.156-201 